\title{
Mixture Effects on Biodegradation Kinetics of Hydrocarbons in Surface Water: Increasing Concentrations Inhibited Degradation whereas Multiple Substrates Did Not
}

\author{
Hammershøj, Rikke Høst; Birch, Heidi; Redman, Aaron D; Mayer, Philipp
}

Published in:

Environmental Science and Technology

Link to article, DOI:

10.1021/acs.est.9b00638

Publication date:

2019

Document Version

Publisher's PDF, also known as Version of record

Link back to DTU Orbit

Citation (APA):

Hammershøj, R. H., Birch, H., Redman, A. D., \& Mayer, P. (2019). Mixture Effects on Biodegradation Kinetics of Hydrocarbons in Surface Water: Increasing Concentrations Inhibited Degradation whereas Multiple Substrates Did Not. Environmental Science and Technology, 53(6), 3087-3094. https://doi.org/10.1021/acs.est.9b00638

\section{General rights}

Copyright and moral rights for the publications made accessible in the public portal are retained by the authors and/or other copyright owners and it is a condition of accessing publications that users recognise and abide by the legal requirements associated with these rights.

- Users may download and print one copy of any publication from the public portal for the purpose of private study or research.

- You may not further distribute the material or use it for any profit-making activity or commercial gain

- You may freely distribute the URL identifying the publication in the public portal 


\title{
Mixture Effects on Biodegradation Kinetics of Hydrocarbons in Surface Water: Increasing Concentrations Inhibited Degradation whereas Multiple Substrates Did Not
}

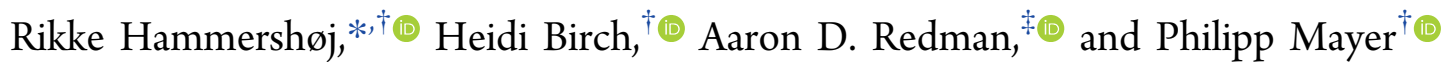 \\ ${ }^{\dagger}$ Technical University of Denmark, Department of Environmental Engineering, Bygningstorvet, Building 115, 2800 Kgs. Lyngby, \\ Denmark \\ ${ }^{\ddagger}$ ExxonMobil Biomedical Science, Inc., Annandale, New Jersey 08801, United States
}

Supporting Information

ABSTRACT: Most biodegradation tests are conducted using single chemicals at high concentrations, although these chemicals are present in the environment as mixtures at low concentrations. A partitioning-based platform was recently developed for biodegradation testing of composed mixtures of hydrophobic chemicals at ng/L to $\mu \mathrm{g} / \mathrm{L}$ concentrations. We used this platform to study the concentration and mixture effect on biodegradation kinetics. Biodegradation tests were conducted in $20 \mathrm{~mL}$ vials using environmental water samples as inocula. Passive dosing was applied (1) to vary initial test concentrations of individual test compounds and (2) to vary the number of mixture components between 1 and
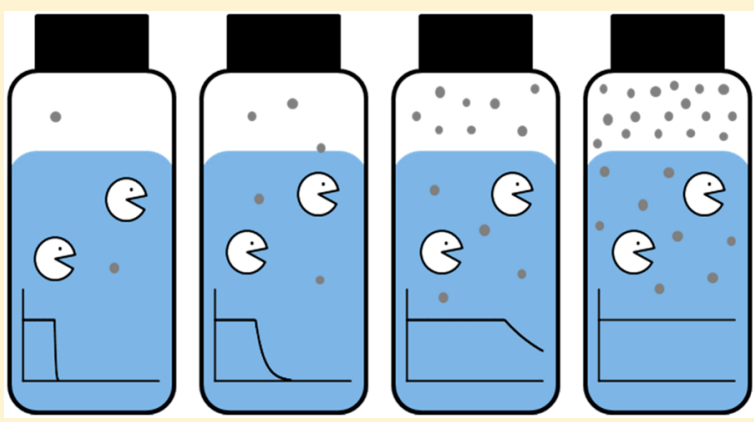

16. Automated solid-phase microextraction coupled to gas chromatography-mass spectrometry was used to measure substrate depletion relative to abiotic controls. The number of mixture components had no or only a limited effect on the biodegradation half times for three compounds when tested at environmentally relevant concentrations. In contrast, longer lag phases and half lives were observed for single compounds when tested at higher concentrations that approached aqueous solubility. The obtained results support that simultaneous testing of multiple chemicals at low concentrations can accelerate the generation of biodegradation kinetic data, which are more environmentally relevant compared with data from tests conducted with single chemicals at much higher concentrations.

\section{INTRODUCTION}

Biodegradation is a main pathway for the removal of many chemicals from the environment and is thus important to include in environmental fate modeling and risk assessment of chemicals. Most regulatory biodegradation tests are conducted on single test chemicals, ${ }^{1}$ whereas biodegradation in the environment takes place in mixtures that include chemicals of natural and anthropogenic origin. Regulatory biodegradation tests are furthermore often conducted at chemical concentrations much higher than what is commonly found in aquatic environments. Recent developments in analytical chemistry and passive dosing allow biodegradation testing and research of composed mixtures of hydrophobic chemicals in the ng/L to $\mu \mathrm{g} / \mathrm{L}$ concentration range. ${ }^{2-4}$ Moving toward biodegradation testing and research of mixtures at low concentrations might improve the relevance of the resulting kinetic data and facilitate the study of mixture effects at environmentally relevant concentrations.

Petroleum products are complex mixtures containing a large number of hydrophobic compounds with different susceptibilities for microbial degradation, ${ }^{5}$ and they are some of the many sources of hydrocarbons in the environment. When chemical mixtures such as petroleum substances enter the environment, substrate interactions can take place and affect the extent and kinetics of microbial degradation. ${ }^{6-8}$ These interactions can either enhance or inhibit biodegradation of the individual hydrocarbons $^{9-11}$ and may reinforce or counteract each other. Positive substrate interactions include cometabolism ${ }^{8}$ and increased biomass growth, ${ }^{10}$ whereas negative interactions include toxicity at elevated concentrations ${ }^{12}$ and competitive inhibition. ${ }^{13}$ When examining the literature, it appears that the extent and direction of the effects of multiple substrates on biodegradation kinetics depend on (i) the complexity of the mixture, that is, the mixture composition and the number of components, ${ }^{9-11,14}$ (ii) the chemical concentrations, ${ }^{9,10,13}$ and (iii) the biomass composition, in particular, whether a pure or mixed bacterial culture is used. ${ }^{15,16}$ There is currently no consensus in the literature on whether the combined mixture effect is more likely to enhance or inhibit biodegradation. Substrate interactions have been reported in systems with up to nine hydrocarbons, ${ }^{10}$ and it has been suggested that the

Received: January 30, 2019

Revised: February 22, 2019

Accepted: February 25, 2019

Published: February 25, 2019 
interactions become more complex with an increasing number of mixture components. ${ }^{9-11,14}$ However, these observations were made at chemical concentrations in the high $\mu \mathrm{g} / \mathrm{L}$ range and low $\mathrm{mg} / \mathrm{L}$ range, typically a factor of $2-10$ below aqueous solubility for each test chemical. Ellis et al. studied the effect of multiple substrates in activated sludge bioreactors and found only small stimulatory effects on biodegradation compared with single-substrate tests. ${ }^{15}$ They argued that the absence of effects was caused by the small amount of substrate compared with the amount of biomass in the test. In the environment, the density of degrader organisms is smaller than that in an activated sludge bioreactor, but the concentrations of hydrocarbons are also lower, and the same causality may apply.

Test concentration is thus another factor that can affect the kinetics of biodegradation. ${ }^{17-21}$ Whereas most biodegradation studies naturally treat the test chemical as a substrate, it is important to remember that at high concentrations most chemicals can be toxic and inhibit metabolic processes. Hydrophobic organic chemicals are known to exert baseline toxicity when a critical concentration is reached in the lipid membranes, which typically requires aqueous concentrations of $1-100 \%$ of solubility (i.e., chemical activity $>0.01){ }^{22}$ Nonpolar organic chemicals are known to inhibit microbial processes at levels similar to those causing effects in other aquatic organisms. ${ }^{23}$ For a chemical mixture, the toxicity can be lower than (antagonism), comparable to (concentration addition) or higher than (synergism) the sum of the individual toxicities. However, recent ecotoxicological studies report a lower concentration threshold for synergistic interactions in multiple stressor studies ${ }^{24}$ and mixture toxicity studies, ${ }^{25}$ which suggests that mixture toxicity interactions require a certain concentration level. Additionally, higher chemical concentrations can lead to a change in the microbial adaptation behavior, selectively induce the growth of competent degraders, and lead to enzyme saturation. ${ }^{19,21,26}$ All of this underlines the importance of conducting biodegradation mixture experiments at environmentally relevant low concentrations. Yet limited literature is available on the effect of multiple substrates on the extent and kinetics of biodegradation at environmentally relevant low concentrations and using environmental inocula.

On the basis of the consulted literature and our previous studies, ${ }^{2-4}$ we formulated two hypotheses: (i) that the total hydrocarbon concentration has a higher impact on biodegradation kinetics than the number of mixture components and (ii) that biodegradation kinetics of hydrocarbons in mixtures at environmentally relevant low concentrations are similar to or faster than those for single hydrocarbons tested at high concentrations. To investigate these hypotheses, we used a recently established partitioning-based experimental platform for determining biodegradation kinetics of composed mixtures of hydrophobic organic chemicals at environmentally relevant concentrations. ${ }^{2}$ It has previously been used in biodegradation testing of hydrophobic chemicals with high air-water partition ratios, ${ }^{2}$ to study the effect of inoculum origin on biodegradation kinetics, ${ }^{3}$ and for determining biodegradation kinetics at low concentrations of 53 hydrocarbons covering five and nine orders of magnitude in $K_{\mathrm{ow}}$ and $K_{\mathrm{aw}}{ }^{4}$ Passive dosing from a preloaded silicone was used to achieve the desired concentrations of each component in an aqueous mixture without the use of a cosolvent, ${ }^{27}$ and environmental water samples containing native microorganisms were used as inocula.
In this study, the aim was to apply the partitioning-based platform (1) to assess the effect of concentration on biodegradation kinetics by changing the concentration of single hydrocarbons by several orders of magnitude and (2) to determine the effect of mixture complexity on biodegradation kinetics at low (total) concentrations by changing the number of mixture components in composed hydrocarbon mixtures. One set of experiments was thus designed to compare the biodegradation kinetics of a single compound when tested at a range of concentrations (concentration level experiment). Another experiment was made to compare the kinetics of individual chemicals at low concentration when tested alone and in mixtures with an increasing number of components (mixture biodegradation experiment). Sixteen petroleum hydrocarbons belonging to eight different hydrocarbon classes were included in the study. Among these, three hydrocarbons were selected as model compounds. This work advances the science of persistence assessments by systematically evaluating concentration and mixture effects on biodegradation kinetics. Polymer-to-water partitioning (i.e., passive dosing) was used here to independently vary the concentration and the mixture composition. Water-to-polymer partitioning (i.e., solid-phase microextraction) was used for automated measurements of primary biodegradation at various concentrations.

\section{EXPERIMENTAL SECTION}

Materials. Sixteen chemicals were included in this study: 1,2,4-trimethylbenzene, trans-decahydronaphthalene (transdecalin), $n$-decane, naphthalene, tetrahydronaphthalene (tetralin), bicyclohexyl, $p$-xylene, and biphenyl (purity $\geq 98 \%$, SigmaAldrich, Denmark); 2-methylnonane, cis-1,2-dimethylcyclohexane, $n$-dodecane, 2,3-dimethylheptane, $n$-octylcyclohexane, and $1,2,3,4,5,6,7,8$-octahydrophenanthrene (purity $\geq 98 \%$, TCI Chemicals, Belgium); and perhydrofluorene and dimethylisopropyl-perhydrophenanthrene (fichtelite) (purity >97.5 and 99.5\%, respectively, Chiron, Norway). 1-Octanol was used as a readily degradable reference compound ( $\geq 99 \%$ purity, SigmaAldrich, Denmark). Custom-made translucent silicone rods (3 $\mathrm{mm}$ diameter polydimethylsiloxane (PDMS), Altec, England) were used as passive dosing phase, and ethyl acetate $(\geq 99.7 \%$ purity, Sigma-Aldrich) and ethanol (absolute, VWR International, Denmark) were used to rinse the silicone rods. Ultrapure water was produced with a LaboStar 1-DI ultrapure water system (SGwater, Germany).

Passive Dosing from a Silicone Rod To Prepare Stock Solutions. Silicone rods were rinsed with deionized water to remove talcum and dried twice with lint-free tissue. The rods were then soaked in ethyl acetate for $24 \mathrm{~h}$, soaked in ethanol for $24 \mathrm{~h}$, and, finally, dried at $120{ }^{\circ} \mathrm{C}$ for $2 \mathrm{~h}$.

Passive dosing systems were prepared in $100 \mathrm{~mL}$ amber glass serum bottles with a 20.0 or $10.0 \mathrm{~g}$ silicone rod. The amount of test chemical needed to saturate the silicone was determined gravimetrically for each chemical. The rods were then loaded by adding an amount of liquid neat chemical or chemical mixture, which was completely absorbed into the silicone rod. The added amounts corresponded to between 0.05 and $1 \%$ of saturation for the $20 \mathrm{~g}$ silicone rods and $80 \%$ for the $10 \mathrm{~g}$ rods. The chemicals were given $48 \mathrm{~h}$ (at $\sim 10 \mathrm{rpm}$ ) to absorb into the rods. The rods were then wiped off twice with lint-free tissue, rinsed once with ultrapure water, and transferred to clean bottles. All loadings were done at $20{ }^{\circ} \mathrm{C}$. 


\section{Mixture biodegradation experiment} Mixture constituents
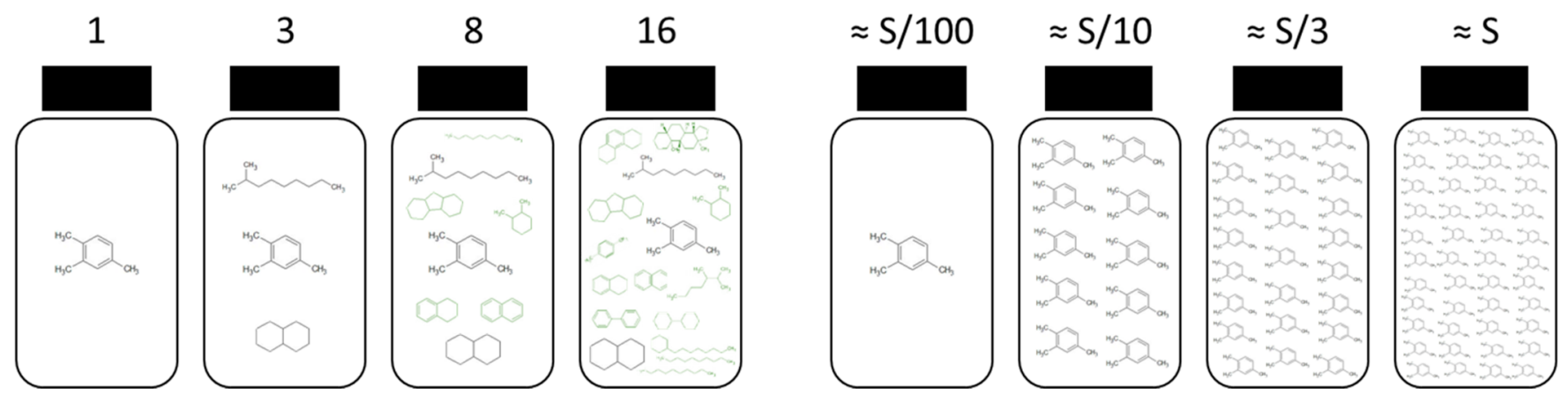

Figure 1. Overview of tests conducted in the mixture biodegradation experiment and concentration level experiment(s) using 1,2,4trimethylbenzene as example.

Stock solutions were generated by equilibrating $65 \mathrm{~mL}$ of ultrapure water or test water with the loaded silicone rods for $>1 \mathrm{~h}$ at $60 \mathrm{rpm}$ horizontal rolling.

Test Water. Surface water was collected from a rural stream (Fønstrup stream, Denmark) with no direct agricultural, industrial, or domestic inputs. ${ }^{28}$ Water samples were used as inoculum without pretreatment within $24 \mathrm{~h}$ and were stored at $4{ }^{\circ} \mathrm{C}$ until use. Two batches of water were collected: one on November 3, 2016 and one on June 12, 2017. Water temperature and heterotrophic plate count were lower in November than in June $\left(9{ }^{\circ} \mathrm{C}\right.$ and $4.1 \times 10^{4} \mathrm{CFU} / \mathrm{mL}$ versus $17.7^{\circ} \mathrm{C}$ and $\left.8.0 \times 10^{4} \mathrm{CFU} / \mathrm{mL}\right)$. Sampling depth, $\mathrm{pH}$, oxygen content, and content of nonvolatile organic carbon were similar for the two batches (Supporting Information S1). Background concentrations of the 16 hydrocarbons were below the detection limit.

Experiments. The mixture biodegradation experiment consisted of parallel biodegradation tests, where three model hydrocarbons (2-methylnonane, 1,2,4-trimethylbenzene, and trans-decalin) were tested alone and in mixtures including 2, 7, and 15 additional hydrocarbons (Figure 1). The model hydrocarbons made up the mixture of three compounds, whereas the mixture of eight compounds included the model hydrocarbons and naphthalene, tetralin, n-decane, cis-1,2dimethylcyclohecane, and perhydorfluorene. The mixture of 16 compounds included the mixture of 8 compounds and additionally $n$-dodecane, 2,3-dimethylheptane, $n$-octylcyclohexane, bicyclohexyl, p-xylene, 1,2,3,4,5,6,7,8-octahydrophenanthrene, and fichtelite. Initial concentrations of the individual hydrocarbons were in the range 0.12 to $69 \mu \mathrm{g} / \mathrm{L}$ (Supporting Information S2) corresponding to two to three orders of magnitude below water solubility for each compound.

The concentration level experiments consisted of parallel biodegradation tests, where two model hydrocarbons were tested separately at different concentrations (Figure 1). In parallel to the mixture experiment, 2-methylnonane and 1,2,4trimethylbenzene were tested at four concentrations ranging from their concentration in the mixture experiment (approximately three orders of magnitude below water solubility) up to a factor of 30 times higher. These concentration levels were chosen to approximately cover the total substrate concentrations in the mixture biodegradation experiment.

After the first tests, it was decided to conduct another concentration-level experiment with higher chemical concentrations. In these tests, 1,2,4-trimethylbenzene and trans- decalin were tested at concentrations between 1 and $\sim 100 \%$ of solubility. We used trans-decalin instead of 2-methylnonane in this experiment because its slower degradation was better suited for studying potential changes in degradation kinetics. However, the measured concentration of trans-decalin in the saturated solution exceeded its reported water solubility ten times. $^{29}$ This was presumably due to an artifact where the dosing from the highly loaded silicone could have released microdroplets to the solution, which is a common technical challenge when working with highly hydrophobic chemicals at the solubility limit. ${ }^{30,31} \mathrm{We}$ only report results from the two tests where the initial concentration did not exceed the reported water solubility. Test concentrations and fractional solubilities are listed in Supporting Information S2.

Biodegradation Testing. Each biodegradation test included an equal number of biotic and abiotic test systems incubated in parallel. At each sampling point, triplicate biotic and abiotic systems were sacrificed for chemical analysis. Test duration $(14,21$, or 28 days) and sampling intervals were predetermined for each biodegradation test based on a simple preliminary test. This was done to optimize the sampling plan as a large number of test systems were prepared and analyzed within a short period of time. Test systems were prepared in 20 $\mathrm{mL}$ amber glass vials with gas-tight stainless-steel screw caps and PTFE-coated silicone septa. All systems had a $5 \mathrm{~mL}$ headspace to ensure aerobic conditions, and test concentrations were sufficiently low to ensure that oxygen depletion did not occur during the experiment. Test systems were incubated at $20 \pm 1{ }^{\circ} \mathrm{C}$ on a benchtop laboratory roller at $\sim 30$ rpm.

In the mixture experiment and first concentration experiment, $1.5 \mathrm{~mL}$ of stock solution, prepared with ultrapure water in passive dosing systems loaded to between 0.05 and $1 \%$, was diluted 10 -fold into $13.5 \mathrm{~mL}$ of test water (biotic systems) or $13.5 \mathrm{~mL}$ of ultrapure water (abiotic systems) containing 50 $\mu \mathrm{g} / \mathrm{L} 1$-octanol (positive control). The biological activity of the first test water batch was confirmed by 1-octanol being $>90 \%$ degraded within 1-3 days in the biotic systems. In the second concentration experiment with higher chemical concentrations, stock solution was prepared by passive dosing of test water or ultrapure water in passive dosing systems loaded to $80 \%$ and was used undiluted or diluted 3 -fold, 10fold, 30 -fold, or 100-fold into test water (biotic systems) or ultrapure water (abiotic systems) to a total volume of $15 \mathrm{~mL}$. The biotic test systems with high concentrations were prepared 
by passive dosing of the surface water to generate a solution that contained both native microorganisms and the test substance at the saturation level. The concentrations in these tests will be described as fractional solubility $S, S / 3, S / 10, S$ / 30 , or $S / 100$, where $S$ is the concentration in water equilibrated with the $80 \%$ saturated PDMS rod. A parallel test with $1 \mathrm{mg} / \mathrm{L} 1$-octanol was included to confirm biological activity in the second batch of test water. This 1-octanol was $>90 \%$ degraded within 1 day.

Chemical Analysis. Automated headspace solid-phase microextraction (HS-SPME) (PAL RSI 85 auto sampler) was applied directly on the test systems and coupled to gas chromatography-mass spectrometry (GC-MS) (Agilent Technologies 7890B/5877A GC7MSD). The automated HSSPME ensured minimal losses, high reproducibility, and high analytical sensitivity and enabled a high throughput of samples. A $100 \mu \mathrm{m}$ PDMS fiber (SUPELCO) was used for 5 or $10 \mathrm{~min}$ extraction at $35^{\circ} \mathrm{C}$ under continuous agitation, succeeded by a 5 min desorption in the injection port at $250{ }^{\circ} \mathrm{C}$ using a split mode in high concentration tests or a splitless mode for $1 \mathrm{~min}$, followed by a split in low concentration tests. The split was between 5:1 and 83:1. Separation was obtained on a DB-5 ms Ultra Inert column from Agilent (122-5562UI) of $60 \mathrm{~m}$ length with a $250 \mu \mathrm{m}$ inner diameter and $0.25 \mu \mathrm{m}$ film thickness using helium as a carrier gas. For tests with one or three chemicals, the GC oven temperature was kept at $60{ }^{\circ} \mathrm{C}$ for $5 \mathrm{~min}$, followed by a ramp of $20{ }^{\circ} \mathrm{C}$ per minute up to $310{ }^{\circ} \mathrm{C}$. For tests with 8 and 16 chemicals, GC oven temperature was kept at $60{ }^{\circ} \mathrm{C}$ for $5 \mathrm{~min}$, followed by a ramp of $15^{\circ} \mathrm{C}$ per minute up to $310{ }^{\circ} \mathrm{C}$ and held for $3 \mathrm{~min}$. All low-concentration test samples were analyzed in SIM mode using a quantifier and at least one qualifier ion for each test chemical, whereas high concentration test samples were analyzed in TIC mode.

Data Treatment. The extracted ion peak area obtained by GC-MS analysis for a test chemical in a biotic test system $\left(A_{\text {biotic }}\right)$ was paired with the peak area from an abiotic test system $\left(A_{\text {abiotic }}\right)$ analyzed immediately after the biotic test system. The ratio between peak areas in the biotic and abiotic test systems was termed $C_{\text {relative }}$ (eq 1 ).

$$
C_{\text {relative }}=\frac{A_{\text {biotic }}}{A_{\text {abiotic }}}
$$

For each time point, three values of $C_{\text {relative }}$ were calculated and then used as replicate input data for further data analysis. A first-order degradation model with lag phase (eq 2) was fitted to these data to obtain estimates of lag phase $\left(t_{\text {lag }}\right)$ and (pseudo) first-order degradation rate constant $\left(k_{\text {system }}\right)$ for each chemical. This was done by the least-squares method in GraphPad Prism v.8; the lag phase was constrained to $\geq 0$, and data were not weighted.

$$
C_{\text {relative }}(t)= \begin{cases}1 & \text { if } t<t_{\text {lag }} \\ \mathrm{e}^{-k_{\text {system }}\left(t-t_{\text {lag }}\right)} & \text { if } t \geq t_{\text {lag }}\end{cases}
$$

Degradation half time $\left(\mathrm{DT}_{50}\right)$, that is, the time until $50 \%$ of a test chemical was degraded, was calculated from best-fit values of lag phase and degradation rate constant obtained by eq 2 (eq 3$) \cdot \ln (2) / k_{\text {system }}$ is equal to the first-order degradation half life $\left(T_{1 / 2}\right)$.

$$
\mathrm{DT}_{50}=t_{\mathrm{lag}}+\frac{\ln (2)}{k_{\text {system }}}
$$

The degradation rate constant, half life, and half time are only reported when at least two measurements were made during the visual degradation phase $\left(10 \%<C_{\text {relative }}<90 \%\right)$. Otherwise, the lag phase and the time between the end of the lag phase and the first measurement of $C_{\text {relative }}<50 \%$ is reported.

The quantification limit was determined as ten times the root-mean-square signal-to-noise ratio calculated in ChemStation (MSD ChemStation Data Analysis Application) for the extracted ion chromatogram. Two measurement points below the limit of quantification, or two points with an extracted ion peak area less than three times the blank peak area, were included in the fitting.

\section{RESULTS AND DISCUSSION}

Degradation curves for all test chemicals and kinetic parameter estimates obtained from model fits are presented in the Supporting Information (Figures S1 and S2 and Tables S3 and S4).

Concentration Level Experiment. In the first concentration experiment, all concentrations were in the $\mathrm{ng} / \mathrm{L}$ to $\mu \mathrm{g} / \mathrm{L}$ range, at least one order of magnitude below aqueous solubility, and overlapped with the range of concentrations used in the mixture biodegradation experiment. 2-Methylnonane was rapidly degraded at the four tested concentrations $(\sim S / 1150$ to $S / 20$; Figure 2$)$. By contrast, 1,2,4-trimethylbenzene was not degraded at any of four tested concentrations $(\sim S / 4700$ to $S / 100$; data not shown) within test durations of 14 or 21 days. Biodegradation of 1,2,4-trimethylbenzene was seen in a prestudy (data not shown) and has been reported in a number of other studies, for example, refs 2-4, 32, and 33. The absence of degradation in this study may be explained by seasonal variations in the density of competent degraders. ${ }^{34,35}$

The second concentration experiment was conducted with higher concentrations covering up to two orders of magnitude in concentrations including aqueous solubility. In these tests, 1,2,4-trimethylbenzene was degraded at the lower three of four concentrations $(\sim S / 100$ to $S / 3$; Figure 2$)$, whereas transDecalin was visibly degraded at the lower of two concentrations $(\sim S / 3$; Figure 2$)$ within the test duration of 28 days.

We generally observed longer apparent lag phases and half lives when concentrations approached the water solubility (Figure 2; Supporting Information S4). For an easier comparison between biodegradation tests with different initial concentrations, biodegradation half times $\left(\mathrm{DT}_{50}\right)$ are shown in Figure 3. $\mathrm{DT}_{50}$ values for 2-methylnonane were similar at the lower three test concentrations and a factor of 1.6 higher at the highest concentration. For 1,2,4-trimethylbenzene, higher initial concentrations resulted in higher $\mathrm{DT}_{50}$ values. The highest relative difference in $\mathrm{DT}_{50}$ for 1,2,4-trimethylbenzene was a factor of 4.2 between the tests with initial concentrations $S / 100$ and $S / 3$, not including the test at concentration $S$, where no visible degradation occurred. trans-Decalin had a $\mathrm{DT}_{50}$ of 23 days at initial concentration $S / 3$, whereas no degradation was observed within test duration at initial concentration $S$.

The observed changes in biodegradation kinetics (lag phase, half life/first-order rate constant, and half times) are consistent with observations by Smith et al., ${ }^{19}$ who studied the biodegradation kinetics of phenanthrene and fluoranthene at different concentrations spanning three to four orders of magnitude. They found that the increase in concentration led to a decrease in the specific first-order mineralization rate 

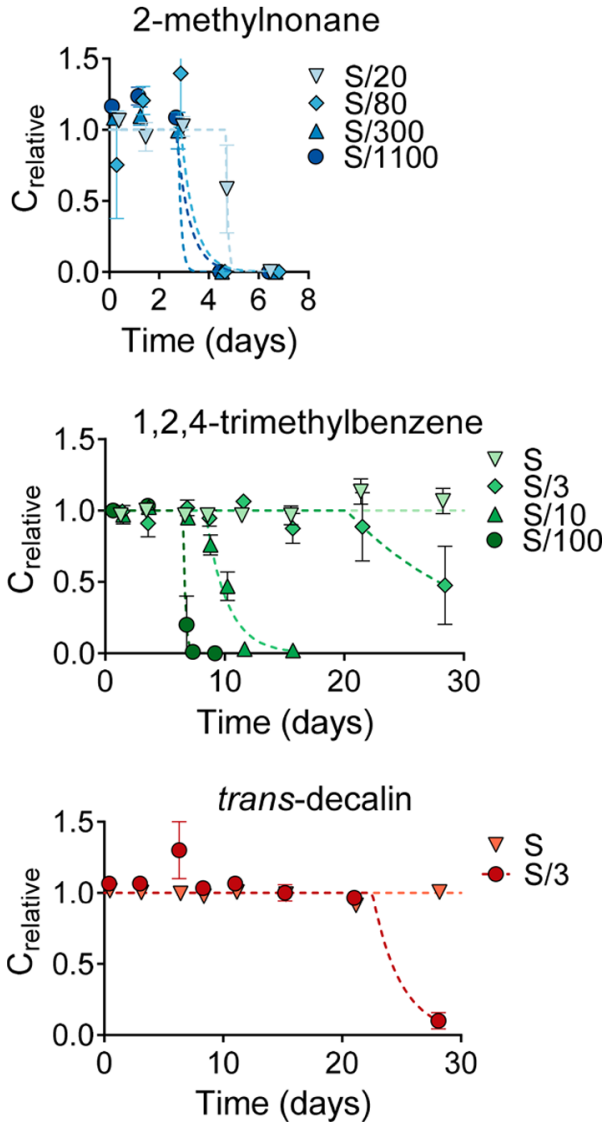

Figure 2. First-order degradation model (dotted lines) fitted to experimental biodegradation data for 2-methylnonane, 1,2,4-trimethylbenzene, and trans-decalin tested at different initial concentrations given as fractional solubility. Error bars represent the standard error of the mean. 1,2,4-Trimethylbenzene and trans-decalin were tested in a different batch of test water than 2-methylnonane.

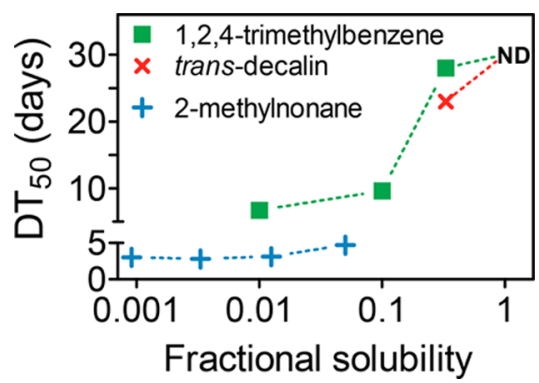

Figure 3. Biodegradation half times for 1,2,4-trimethylbenzene and trans-decalin tested in parallel at different initial concentrations and for 2-methylnonane tested in a different batch of test water. Concentrations are given as fractional solubility. Test duration was 28 days. $\mathrm{ND}=$ no degradation.

constant (time biomass $^{-1}$ ) by a factor of 176 for phenanthrene and 50 for fluoranthene and a corresponding increase in their estimated half lives. The associated mineralization flux (mass time ${ }^{-1}$ biomass $^{-1}$ ) increased with concentration but less than proportionally. Similarly, Prince et al. $^{20}$ observed longer apparent half lives with increasing test concentration for a dispersed crude oil, albeit at concentrations higher than those in our study.

The observed increase in apparent lag phase and half life with higher initial concentrations can be explained by (1) growth-linked kinetics, as described by the Monod equation, ${ }^{36}$ (2) enzyme saturation, as described by Michaelis-Menten kinetics, ${ }^{36}$ and (3) toxic inhibition by the test substance, as described by baseline toxicity and the toxic unit model. ${ }^{2,23}$

(1) The lag phase represents several processes such as acclimatization, adaptation, and growth of specific degraders. ${ }^{36}$ At higher substrate concentrations, a higher biomass concentration will be needed to degrade the substrate, which can lead to the longer apparent lag phases. The initial growth of the biomass may then be the kinetic limiting factor up to the point where the maximum specific growth rate is reached (when $C \gg K_{\mathrm{s}}$ ) and other factors become limiting. ${ }^{36} K_{\mathrm{s}}$ for similar chemicals is in the range $4-200 \mu \mathrm{M}^{36}$ (phenanthrene, toluene, and naphthalene). For 1,2,4-trimethylbenzene with a molar mass of $120 \mathrm{~g} / \mathrm{mol}$, this corresponds to between 480 and $24000 \mu \mathrm{g} / \mathrm{L}$. With 1,2,4-trimethylbenzene concentrations between 1275 and $127500 \mu \mathrm{g} / \mathrm{L}$ in the second concentration experiment, it is thus likely that the highest growth rate was reached in some of these tests.

(2) Biodegradation half lives may depend on substrateenzyme interactions because metabolism will not increase proportionally with the substrate concentrations when these are sufficiently high $\left(C>K_{\mathrm{M}}\right.$, enzyme saturation $) .{ }^{36}$

(3) Figure 3 demonstrates that degradation was reduced at hydrocarbon concentrations near their solubility limits, which is within the reported chemical activity range $(1-100 \%$ of solubility) for baseline toxicity. This was further investigated by plotting lag phases and degradation half times against predicted effect concentrations for microbial end points (target-lipid-model-predicted acute 5th-ile threshold), ${ }^{23}$ including several data where biodegradation was not observed within the duration of the test (for details, see the Supporting Information S5). The exposure concentrations $\left(C_{\mathrm{w}}\right)$ for the three test chemicals were normalized to the predicted $\mathrm{EC}_{50}$ (i.e., toxic unit $\left.(\mathrm{TU})=C_{\mathrm{w}} / \mathrm{EC}_{50}\right)$ to adjust for different effective concentrations of the test chemicals. The lag phases and half times appear to increase sharply around TU $=1$ (Figure S3). This is consistent with the hypothesized toxicity limiting the growth of degrader organisms and their metabolic activity at concentrations near the solubility limit or differential sensitivities among the population of degrader organisms, which will lead to longer lag phases and half lives.

In the current study, we do not distinguish concentration effects caused by growth-linked kinetics, enzyme saturation, and inhibition due to toxicity, and the observed delay in biodegradation at higher hydrocarbon concentrations might thus have several causes and even involve interactions between them.

Mixture Biodegradation Experiment. 2-Methylnonane and trans-decalin were degraded when tested alone and in mixtures of 3, 8, and 16 components (Figure 4A). 1,2,4Trimethylbenzene was degraded in the mixtures of 3,8 , and 16 components but not when tested alone within the 14 day test duration (Figure 4A). For 1,2,4-trimethylbenzene tested alone, however, the test was terminated 3 days after the end of the lag phase in the tests with 3,8 , and 16 components. The exclusion of specific degraders in the test water sample due to seasonal variations could explain the long lag phase, or the absence of degradation, for 1,2,4-trimethylbenzene $\mathrm{s}^{34,37}$ but not the discrepancy between 1,2,4-trimethylbenzene tested alone and in the mixtures.

For an easier comparison between biodegradation tests with different numbers of hydrocarbons, biodegradation half times 

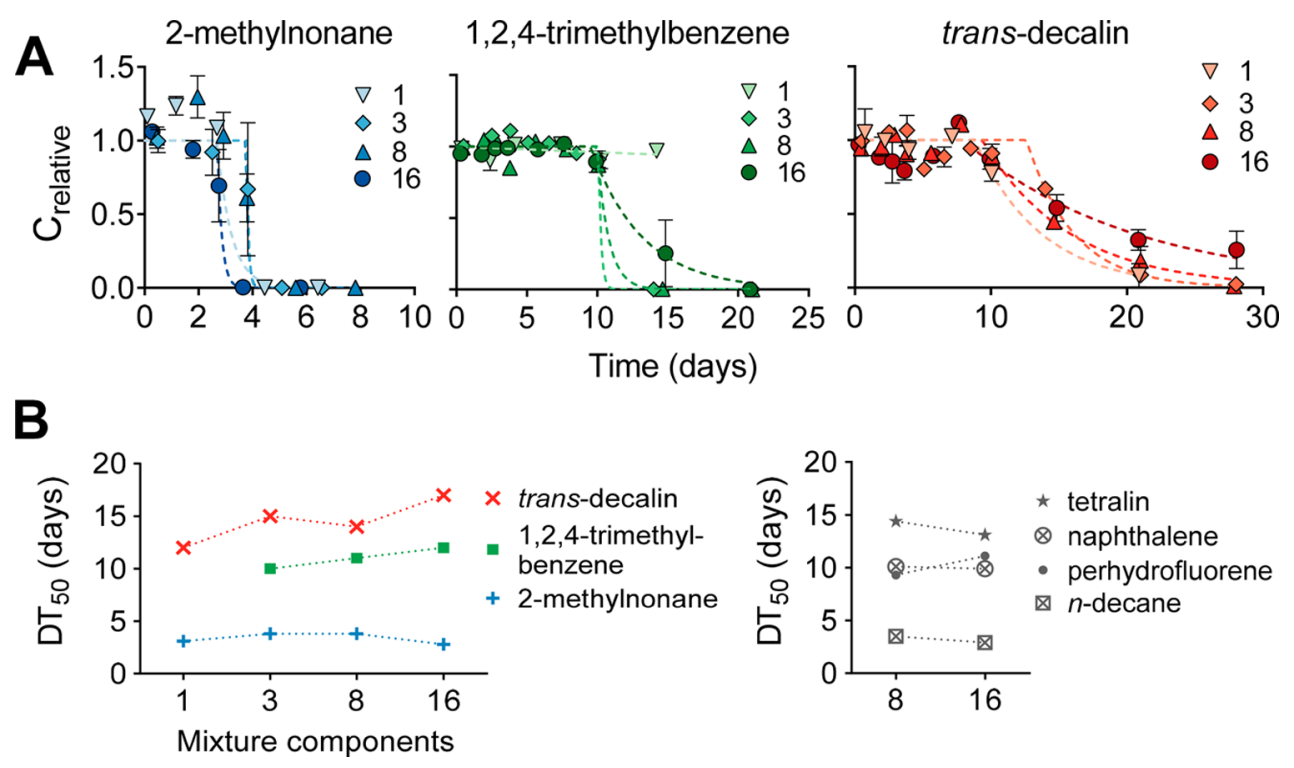

Figure 4. (A) First-order degradation model (dotted lines) fitted to experimental biodegradation data for three model compounds tested in mixtures of $1,3,8$, and 16 hydrocarbons. Initial concentrations were three orders of magnitude below water solubility for each hydrocarbon. Error bars represent standard error of the mean. (B) Biodegradation half times for trans-decalin, 1,2,4-trimethylbenzene, and 2-methylnonane tested in mixtures of $1,3,8$, and 16 hydrocarbons and for tetralin, naphthalene, perhydrofluorene, and $n$-decane that were also part of the mixtures of 8 and 16 hydrocarbons.

were calculated for the three model compounds and for four of the five additional test compounds that were also part of the mixtures of 8 and 16 hydrocarbons (tetralin, naphthalene, perhydrofluorene, and $n$-decane; Figure 4B). No marked effect was observed for the number of mixture constituents on biodegradation half time for any of these hydrocarbons; the largest observed difference in degradation half times was a factor of 1.4 between trans-decalin tested alone and in the mixture of 16 hydrocarbons. The fifth test compound included in tests of both 8 and 16 hydrocarbons, cis-1,2-dimethylcyclohexane, was only partially degraded in the mixture of 8 hydrocarbons and was not degraded in the mixture of 16 hydrocarbons (Figure S1). Thus the biodegradation half times were largely constant with an increasing number of mixture constituents for the three model hydrocarbons and the five hydrocarbons that were also included in the tests with 8 and 16 components. The exception was a longer lag phase, or lack of degradation, of 1,2,4-trimethylbenzene when tested alone and of cis-1,2-dimethylcyclohexane in the mixture of 16 hydrocarbons.

Whereas we observed only limited effects of multiple substrates on biodegradation kinetics of the individual hydrocarbons, other studies have reported pronounced multiple substrate effects in mixtures of up to nine hydrocarbons. $^{9-11,14}$ One possible explanation for the limited effects in our study is that positive and negative substrate interactions counteracted each other. ${ }^{10}$ This could arguably be the case, but larger differences would then be expected between mixtures with a different number of components. A more likely explanation for the apparent lack of multiple substrate effects is the initial test concentration. Whereas chemical concentrations in this mixture study were two to three orders of magnitude below solubility, the majority of the reported studies used chemical concentrations from one order of magnitude below and up to aqueous solubility. Considering the results of our concentration experiments, it could be hypothesized that some of the effects of multiple substrates reported by other studies were confounded by large differences in the total substrate concentrations in those tests. At environmentally relevant low concentrations, native microorganisms can utilize several substrates simultaneously, and mixed substrate growth and utilization is common in the environment. ${ }^{38,39}$ This could explain why only limited multiple substrate effects were observed on the primary biodegradation half times in this study.

Implications for Biodegradation Testing. This study was initiated with the primary purpose of investigating to which extent the number of constituents in a mixture affects the biodegradation kinetics of individual chemicals. The largest relative difference observed in the mixture experiment was the $\mathrm{DT}_{50}$ for trans-decalin being 1.4 times lower when tested alone than in a mixture of 16 hydrocarbons. By contrast, we observed differences in $\mathrm{DT}_{50}$ by up to a factor of 4.2 in the concentration experiment, not including data where biodegradation was not observed within the duration of the test. Hence, the biodegradation half times were affected more by the initial substrate concentration than by the number of components in the mixtures.

Biodegradation kinetic data are crucial for environmental fate modeling and risk assessment. While acknowledging that biodegradation kinetics depend on many factors and cannot be fully represented with simple first-order models, current persistency assessments are based on biodegradation kinetic parameters such as half times and half lives. An increase in biodegradation half lives with increasing concentration, as seen for 1,2,4-trimethylbenzene (Table S5), will lead to a distortion between laboratory test results obtained at a high concentration and actual biodegradation in the environment at much lower concentrations. This underlines the importance of using kinetic data from biodegradation experiments conducted at environmentally relevant concentrations in environmental fate modeling. Recent developments in analytical chemistry make biodegradation kinetic studies at such low concentrations feasible, at least for evaluating primary degradation. 
The negligible effect of multiple substrates we observed at low hydrocarbon concentrations implies that biodegradation simulation testing of several compounds can reasonably be done simultaneously. This can yield a higher number of wellaligned biodegradation data, as kinetics are obtained from the same test and with the same inoculum. These data will often be more environmentally relevant because coexposure to mixtures at low concentration is the most common situation in the environment. Biodegradation testing of mixtures at low concentrations could therefore accelerate the generation of environmentally relevant biodegradation data.

The limited effect of multiple substrates at low concentrations has additional implications that go beyond biodegradation testing. McLachlan and coauthors have recently suggested using benchmarking to strengthen the assessment of persistence and more specifically to assess biodegradation of a chemical on a relative scale against benchmark chemicals with known biodegradation and persistency profiles. ${ }^{40}$ This strategy certainly has a lot of potential but requires that benchmark chemicals can be included in biodegradation experiments without considerably biasing the biodegradation result of the target chemical(s). The present study supports that this is feasible, at least when testing at low substrate concentrations. Furthermore, biodegradation kinetic data for individual chemicals are often used as input in models for predicting biodegradation, exposure, and fate of complex mixtures. ${ }^{15}$ The present study supports the important assumption that biodegradation kinetics can reasonably be modeled separately for each mixture constituent and then combined without taking substrate interactions into account, at least for lowconcentration exposure scenarios.

The methodology and observations of the present study provide a good starting point for (1) investigating if a lower concentration threshold exists for mixture effects on biodegradation kinetics, (2) new experiments directed at distinguishing growth-linked biodegradation and enzyme saturation from toxicity as causes for the delayed degradation at high concentrations, and (3) further biodegradation kinetic studies of chemicals in the presence and absence of relevant cosubstrate mixtures. Furthermore, this testing of mixtures at low concentration could be extended to multicomponent substances and chemical substances of Unknown or Variable Composition, Complex Reaction Products, and Biological Materials (UVCBs).

\section{ASSOCIATED CONTENT}

\section{S Supporting Information}

The Supporting Information is available free of charge on the ACS Publications website at DOI: 10.1021/acs.est.9b00638.

Characterization of environmental test water, initial concentrations, biodegradation curves, biodegradation kinetics (lag phase, first-order rate constant, half life, and half time), and toxicity modeling analysis (PDF)

\section{AUTHOR INFORMATION}

\section{Corresponding Author}

*E-mail: rikkehh@env.dtu.dk.

\section{ORCID}

Rikke Hammershøj: 0000-0001-7422-7863

Heidi Birch: 0000-0002-7152-3832

Aaron D. Redman: 0000-0002-5933-7906

Philipp Mayer: 0000-0001-5138-7506

\section{Notes}

The authors declare no competing financial interest.

\section{ACKNOWLEDGMENTS}

This study was funded by Concawe. We are grateful to Hanne Bøggild for technical assistance in the laboratory, Chris Hughes and the Concawe Ecology Group for their comments on the draft manuscript, and three anonymous reviewers for helpful suggestions.

\section{REFERENCES}

(1) OECD. Revised Introduction to the OECD Guidelines for Testing of Chemicals, Section 3. In OECD Guidelines for the Testing of Chemicals; OECD Publishing: Paris, 2006.

(2) Birch, H.; Andersen, H. R.; Comber, M.; Mayer, P. Biodegradation testing of chemicals with high Henry's constants Separating mass and effective concentration reveals higher rate constants. Chemosphere 2017, 174, 716-721.

(3) Birch, H.; Hammershøj, R.; Comber, M.; Mayer, P. Biodegradation of hydrocarbon mixtures in surface waters at environmentally relevant levels - Effect of inoculum origin on kinetics and sequence of degradation. Chemosphere 2017, 184, 400407.

(4) Birch, H.; Hammershøj, R.; Mayer, P. Determining Biodegradation Kinetics of Hydrocarbons at Low Concentrations: Covering 5 and 9 Orders of Magnitude of $K_{\text {ow }}$ and $K_{\text {aw }}$. Environ. Sci. Technol. 2018, 52 (4), 2143-2151.

(5) Head, I. M.; Jones, D. M.; Röling, W. F. M. Marine microorganisms make a meal of oil. Nat. Rev. Microbiol. 2006, 4 (3), 173-182.

(6) Horvath, R. S. Microbial co-metabolism and the degradation of organic compounds in nature. Bacteriol. Rev. 1972, 36 (2), 146-155.

(7) Arvin, E.; Jensen, B. K.; Gundersen, A. T. Substrate interactions during aerobic biodegradation of benzene. Appl. Environ. Microbiol. 1989, 55 (12), 3221-3225.

(8) Chang, M. K.; Voice, T. C.; Criddle, C. S. Kinetics of competitive inhibition and cometabolism in the biodegradation of benzene, toluene, and p-xylene by two Pseudomonas isolates. Biotechnol. Bioeng. 1993, 41 (11), 1057-1065.

(9) Desai, A. M.; Autenrieth, R. L.; Dimitriou-Christidis, P.; McDonald, T. J. Biodegradation kinetics of select polycyclic aromatic hydrocarbon (PAH) mixtures by Sphingomonas paucimobilis EPA505. Biodegradation 2008, 19 (2), 223-233.

(10) Knightes, C. D.; Peters, C. A. Multisubstrate biodegradation kinetics for binary and complex mixtures of polycyclic aromatic hydrocarbons. Environ. Toxicol. Chem. 2006, 25 (7), 1746-1756.

(11) Guha, S.; Peters, C. A.; Jaffé, P. R. Multisubstrate biodegradation kinetics of naphthalene, phenanthrene, and pyrene mixtures. Biotechnol. Bioeng. 1999, 65 (5), 491-499.

(12) Bouchez, M.; Blanchet, D.; Vandecasteele, J. P. Degradation of polycyclic aromatic hydrocarbons by pure strains and by defined strain associations: inhibition phenomena and cometabolism. Appl. Microbiol. Biotechnol. 1995, 43 (1), 156-164.

(13) Stringfellow, W. T.; Aitken, M. D. Competitive metabolism of naphthalene, methylnaphthalenes, and fluorene by phenanthrenedegrading pseudomonads. Appl. Environ. Microbiol. 1995, 61 (1), $357-362$.

(14) Dimitriou-Christidis, P.; Autenrieth, R. L. Kinetics of biodegradation of binary and ternary mixtures of PAHs. Biotechnol. Bioeng. 2007, 97 (4), 788-800.

(15) Ellis, T. G.; Smets, B. F.; Grady, C. P. L. Effect of simultaneous biodegradation of multiple substrates on the extant biodegradation kinetics of individual substrates. Water Environ. Res. 1998, 70, 27-38.

(16) Reardon, K. F.; Mosteller, D. C.; Rogers, J. B.; DuTeau, N. M.; Kim, K. H. Biodegradation kinetics of aromatic hydrocarbon mixtures by pure and mixed bacterial cultures. Environ. Health Perspect. 2002, 110 (6), 1005-1011. 
(17) Boethling, R. S.; Alexander, M. Effect of Concentration of Organic Chemicals on Their Biodegradation by Natural Microbial Communities. Appl. Environ. Microbiol. 1979, 37 (6), 1211-1216.

(18) Ahtiainen, J.; Aalto, M.; Pessala, P. Biodegradation of chemicals in a standardized test and in environmental conditions. Chemosphere 2003, 51 (6), 529-537.

(19) Smith, K. E. C.; Rein, A.; Trapp, S.; Mayer, P.; Karlson, U. G. Dynamic passive dosing for studying the biotransformation of hydrophobic organic chemicals: Microbial degradation as an example. Environ. Sci. Technol. 2012, 46 (9), 4852-4860.

(20) Prince, R. C.; Butler, J. D.; Redman, A. D. The Rate of Crude Oil Biodegradation in the Sea. Environ. Sci. Technol. 2017, 51 (3), $1278-1284$

(21) Berg, U. T.; Nyholm, N. Biodegradability simulation studies in semicontinuous activated sludge reactors with low $(\mu \mathrm{g} / \mathrm{L}$ range $)$ and standard (ppm range) chemical concentrations. Chemosphere 1996, 33 (4), 711-735.

(22) Schmidt, S. N.; Mayer, P. Linking algal growth inhibition to chemical activity: Baseline toxicity required $1 \%$ of saturation. Chemosphere 2015, 120, 305-308.

(23) Redman, A.; McGrath, J.; Febbo, E.; Parkerton, T.; Letinski, D.; Connelly, M.; Winkelmann, D.; Di Toro, D. Application of the target lipid model for deriving predicted no-effect concentrations for wastewater organisms. Environ. Toxicol. Chem. 2007, 26 (11), 2317-2331.

(24) Schmidt, S. N.; Holmstrup, M.; Damgaard, C.; Mayer, P. Simultaneous control of phenanthrene and drought by dual exposure system: The degree of synergistic interactions in springtails was exposure dependent. Environ. Sci. Technol. 2014, 48 (16), 9737-9744.

(25) Bjergager, M. B. A.; Dalhoff, K.; Kretschmann, A.; Nørgaard, K. B.; Mayer, P.; Cedergreen, N. Determining lower threshold concentrations for synergistic effects. Aquat. Toxicol. 2017, 182, 79-90.

(26) Grady, C. P. L.; Smets, B. F.; Barbeau, D. S. Variability in kinetic parameter estimates: A review of possible causes and a proposed terminology. Water Res. 1996, 30 (3), 742-748.

(27) Smith, K. E. C.; Dom, N.; Blust, R.; Mayer, P. Controlling and maintaining exposure of hydrophobic organic compounds in aquatic toxicity tests by passive dosing. Aquat. Toxicol. 2010, 98 (1), 15-24.

(28) The Danish Environmental Protection Agency. MiljøGIS for Vandområdeplanerne 2015-2021. http://miljoegis.mim.dk/ cbkort?profile=vandrammedirektiv2-2016 (accessed Nov 7, 2017).

(29) Tolls, J.; van Dijk, J.; Verbruggen, E. J. M.; Hermens, J. L. M.; Loeprecht, B.; Schüürmann, G. Aqueous Solubility-Molecular Size Relationships: A Mechanistic Case Study Using C10- to C19-Alkanes. J. Phys. Chem. A 2002, 106 (11), 2760-2765.

(30) Verbruggen, E. M. J.; Hermens, J. L. M.; Tolls, J. Physicochemical Properties of Higher Nonaromatic Hydrocarbons: A Literature Study. J. Phys. Chem. Ref. Data 2000, 29 (6), 1435-1446.

(31) Letinski, D. J.; Parkerton, T. F.; Redman, A. D.; Connelly, M. J.; Peterson, B. Water solubility of selected C9-C18 alkanes using a slow-stir technique: Comparison to structure-property models. Chemosphere 2016, 150, 416-423.

(32) Solano-Serena, F.; Marchal, R.; Ropars, M.; Lebeault, J. M.; Vandecasteele, J. P. Biodegradation of gasoline: Kinetics, mass balance and fate of individual hydrocarbons. J. Appl. Microbiol. 1999, 86 (6), $1008-1016$

(33) Prince, R. C.; Parkerton, T. F.; Lee, C. The Primary Aerobic Biodegradation of Gasoline Hydrocarbons. Environ. Sci. Technol. 2007, 41 (9), 3316-3321.

(34) Vergeynst, L.; Kjeldsen, K. U.; Lassen, P.; Rysgaard, S. Bacterial community succession and degradation patterns of hydrocarbons in seawater at low temperature. J. Hazard. Mater. 2018, 353, 127-134. (35) Van Hamme, J. D.; Singh, A.; Ward, O. P. Recent Advances in Petroleum Microbiology. Microbiol. Mol. Biol. Rev. 2003, 67 (4), 503549.

(36) Schwarzenbach, R. P.; Gschwend, P. M.; Imboden, D. M. Biological Transformations. In Environmental Organic Chemistry; John Wiley \& Sons, Inc.: Hoboken, NJ, 2005; pp 687-773.
(37) Martin, T. J.; Snape, J. R.; Bartram, A.; Robson, A.; Acharya, K.; Davenport, R. J. Environmentally Relevant Inoculum Concentrations Improve the Reliability of Persistent Assessments in Biodegradation Screening Tests. Environ. Sci. Technol. 2017, 51 (5), 3065-3073.

(38) Egli, T. How to live at very low substrate concentration. Water Res. 2010, 44 (17), 4826-4837.

(39) Button, D. K. Kinetics and Physiology at Vanishingly Small Substrate Concentrations. In Cellular Ecophysiology of Microbe: Hydrocarbon and Lipid Interactions; Krell, T., Ed.; Springer International Publishing: Cham, Switzerland, 2018; pp 449-461.

(40) McLachlan, M. S.; Zou, H.; Gouin, T. Using Benchmarking to Strengthen the Assessment of Persistence. Environ. Sci. Technol. 2017, $51(1), 4-11$. 